\title{
"Atelier Digital", uma proposta inovadora: relato de experiência com a Terceira Idade
}

\author{
Liliana Maria Passerino \\ Feevale - Instituto de Ciências Exatas e Tecnológicas \\ liliana@feevale.br \\ Maria Rosangela Bez \\ Feevale - Instituto de Ciências Exatas e Tecnológicas \\ mariabez@feevale.br \\ Paulo Roberto Pasqualotti \\ Feevale - Instituto de Ciências Exatas e Tecnológicas \\ ppasqualotti@feevale.br
}

\begin{abstract}
Resumo. Este artigo apresenta o "Atelier Digital", uma proposta diferenciada de acesso à tecnologia para terceira idade, que expressa a integração entre o "criar" e o "descobrir" percebendo a arte como a universalidade do saber. Tem como proposta perceber o idoso como único em sua necessidade, mas ao mesmo tempo integrado ao grupo e comunidade onde se insere, fazendo parte e interagindo socialmente, mas ao mesmo tempo sendo sujeito ativo de sua própria história, utilizando-se das Tecnologias da Informação para sua aprendizagem e desenvolvimento. Neste artigo é apresentado um relato de experiências com o que está sendo realizado nos encontros do Atelier Digital e nas oficinas criadas para complementar esse projeto inovador.
\end{abstract}

Palavras-chave: Terceira Idade, inclusão digital, Tecnologia da Informação.

"Atelier Digital", a novel proposal: report of our experience with old-age people

Abtract: This paper presents a differentiate proposal for technology accessibility to oldage people, called "Atelier Digital", which represents the integration between "create" and "discovery" perceiving the art as the universality of knowing. Our aim is to considerate old-age people as an individual regarding their own needs and, at the same time, integrated with their community. This people interacting socially and, also at the same time, are subject of their own history. We use the information technology to lead this learn and development process. Here we report our experience about what we have been realized at the "Atelier Digital" meetings and workgroups, made to complement our novel project.

Key-words: old-age Age, digital inclusion, Information Technology

\section{Introdução}

Pelo fato das Tecnologias de Informação (TI) afetarem um número cada vez maior de pessoas em todo o mundo e de existirem diferentes grupos excluídos dentro da 
sociedade, propõe-se pensar o processo de Inclusão Digital para além do manuseio tecnológico.

Acredita-se que o impacto das TI não é uniforme em todos os setores, mas dependente de variáveis sócio-históricas, aspectos individuais e organizacionais em níveis macro e micro sociais: governo, sociedade, família, entre outras organizações nas quais os indivíduos se estruturam (Passerino e Pasqualotti, 2006). Pensando num nível micro, e estudando uma organização social particular como a família, percebe-se que o impacto é, também, diferente para cada um dos seus membros (pai, filho, avôs, netos, etc.). Isso se deve especialmente a variáveis individuais que dizem respeito à história de cada sujeito em transformação e seu contexto sócio-histórico de desenvolvimento.

Nesse sentido, a população idosa frente a uma sociedade cada vez mais tecnológica é duplamente excluída: de acesso e de apropriação. Às vezes a causa da exclusão é a dificuldade de manusear a tecnologia e de ter possibilidades e oportunidades de acesso. Aqui então se apresentam variáveis sócio-econômicas e psico-biológicas relacionadas com o envelhecimento humano. Porém, existe outra variável de exclusão, pouco considerada e muitas vezes ignorada no desenvolvimento de novas tecnologias: a funcionalidade da tecnologia que provoca uma exclusão decorrente de variáveis sóciocognitivas.

Cada indivíduo, diante das novas tecnologias, possui necessidades específicas, expectativas próprias, realidades diferenciadas, habilidades e conhecimentos já adquiridos, sendo, portanto, necessário trabalhar a inclusão tecnológica de forma continuada, diferenciando e atendendo a individualidade e as especificidades dos sujeitos quanto as suas facilidades e/ou dificuldades para a apropriação das novas formas para o "fazer" por meio das Tecnologias de Informação.

Esse espaço de inclusão digital para a terceira idade foi denominado de "Atelier Digital", que expressa a integração entre o "criar" e o "descobrir", percebendo a arte como a universalidade do saber. Tem como objetivo atender aos idosos, participantes dos grupos da terceira idade da Feevale quanto as suas necessidade de conhecimento e habilidades, para tornarem-se sujeitos atuantes dentro de uma realidade tecnológica que exclui quem não domina seus recursos e seu uso. Da mesma forma, visa promover a inclusão digital a partir do atendimento individual das demandas de desenvolvimento e apropriação das TI.

A partir da percepção de que o sujeito interage e faz parte de um meio social e que possui necessidades comuns do coletivo, são realizadas oficinas específicas, visando o desenvolvimento do grupo.

Estudos nessa área de tecnologia e terceira idade desenvolvidos por Kachar (2003); Sá ( 1999) e Novaes (1997), mostram que existem mudanças cognitivas e sociais na terceira idade dos que participam de projetos de inclusão digital, e que é possível identificar efeitos sobre o envelhecimento na aquisição e aplicação dos novos recursos tecnológicos.

O Atelier Digital também se apresenta como uma oportunidade de resgate dos espaços de atuação do idoso frente a sua realidade. Integrante de uma geração que sempre determinou os rumos de suas ações, que tomava as decisões, vê-se diante de um dilema, e de um problema, ao perder sua capacidade como sujeito ativo e atuante, nos seus espaços para as gerações posteriores (filhos, netos, ...), cuja habilidade e conhecimento com as tecnologias tornam o partilhar de recursos computacionais (muitas vezes o computador da família) praticamente impossível. 
Percebe-se pelas falas dos alunos da terceira idade, que tão importante, ou mais, do que adquirir conhecimento e habilidade com o computador, é ter a capacidade de utilizar a tecnologia de forma independente, correta e sem os receios em "estragar" ou perder os trabalhos de outros usuários.

O presente estudo é resultado de uma pesquisa maior que visa esclarecer o peso dos aspectos bio-psico-sociais incidentes no processo de manifestação da depressão em idosos e sobre as possíveis intervenções tecnológicas num processo de inclusão digital ${ }^{1}$.

O relato de experiência que será aqui descrito, refere-se às atividades do Atelier Digital, uma proposta de inclusão digital diferenciada em TIC's para a terceira idade. A seguir é apresentada a contextualização da pesquisa e o relato de experiência.

\section{Contextualizando a pesquisa: A Terceira Idade tratamento diferenciado no acesso compreensão da TI}

Existem diferenças entre as faixas etárias na forma em que deve ser introduzido a aprendizagem e o domínio do computador. Numa comparação entre o ensino de crianças, adultos e idosos com o computador, é importante desenvolver estratégias, levando em conta as características de cada um, condições sociais, respeitando o ritmo e o tempo para aprender, sem esquecer das limitações físicas e cognitivas.

Atender às questões de usabilidade e de acessibilidade também é fundamental para permitir ao usuário utilizar da melhor forma os recursos do computador. As interfaces computacionais são dinâmicas, com propriedades e facilidades que permitem adequá-las e otimizá-las ao uso. Dessa forma tornar uma aplicação acessível é adequá-las às necessidades e demandas de quem interage e utiliza essa aplicação. De acordo com Dias (2003, p. 28), "a usabilidade pode ser considerada uma qualidade de uso, entre o usuário e o sistema, sendo dependente das características de ambos... O mesmo sistema pode ser excelente para algumas pessoas e inadequado ou inaceitável para outras.".

Ao buscar atender à adequação e usabilidade no uso das tecnologias pelos idosos, todas as atividades do Atelier Digital são planejadas considerando essas premissas e critérios, desde o uso dos laboratórios, dos materiais instrucionais criados para esse fim às interfaces das aplicações desenvolvidas para os alunos do Atelier Digital, em especial o uso da WEB.

Para Kachar (2003), na sociedade contemporânea a socialização incorpora as relações produzidas pela rede de interconexões de pessoas entre si mediadas pelas TI. A geração nascida no universo de ícones, imagens, botões e teclas transitam na operacionalização com desenvoltura na cena visionária de quase ficção científica, mas outra, nascida em tempos de relativa estabilidade, convive de forma conflituosa com as rápidas e complexas mudanças tecnológicas, cuja progressão é geométrica.

Para Pretto (1996) o analfabeto do futuro será o indivíduo que não souber decifrar a nova linguagem gerada pelos meios de comunicação A nova geração é introduzida nesse universo já a partir do nascimento e por isso sua intimidade com os meios eletrônicos ocorre numa relação de identificação e fascinação. Por outro lado, os idosos têm revelado suas dificuldades em entender a nova linguagem e em lidar com os

\footnotetext{
1 A pesquisa denominada INTERDIG - Intervenção Digital com Pessoas Idosas Depressivas é desenvolvida em consórcio entre as Universidades de Passo Fundo, UFRGS, Feevale, Unicamp, Furg, Unisinos, Unijuí, Fag e Ceulp. 
avanços tecnológicos até mesmo nas questões mais básicas como os eletrodomésticos, celulares, caixas eletrônicos. Conseqüentemente, aumenta o número de idosos iletrados em Informática, ou analfabetos digitais, em todas as áreas da sociedade.

Esse novo universo de relações, comunicações e trânsito de informações pode se tornar mais um elemento de exclusão para o idoso, tirando-lhe a oportunidade de participar do presente, marginalizando-o e exilando-o no tempo da geração anterior, relegando à função social de memória, de passado. Para inserir-se na sociedade atual é preciso ter acesso à linguagem da Informática, dispondo dela para liberar-se do fardo de ser visto como um indivíduo ultrapassado e descontextualizado do mundo atual.

Há muitos cursos de Introdução à Informática oferecidos por empresas especializadas, mas poucos que se destinam à terceira idade. Diversas oficinas têm sido ministradas, mas ainda de forma muito técnica. Percebe-se que este público alvo precisa de um tratamento diferenciado dentro de suas expectativas e possibilidades.

Segundo Jorge (2006), no caso da terceira idade cabe analisar, então, para que vai lhe servir o computador. Esse é o ponto inicial para o aprendizado. A pessoa precisa perceber no computador - e na Informática - um aliado para facilitar a vida no seu dia-adia. Entender que atividades realizadas até então de forma trabalhosa, muitas vezes braçal, hoje são feitas com alguns cliques do mouse. É necessário olhar a sua volta e ver o que as pessoas estão fazendo e conseguindo com a utilização de um microcomputador e a Internet.

Algumas iniciativas de universidades abertas para terceira idade oferecem oportunidades de atividades e cursos voltados para os idosos, porém ainda escassas, nem sempre apresentando uma metodologia de ensino aprendizagem das TI de forma especializada.

Portanto, a proposta de educação para idosos, incluindo-se especialmente a informática, deve considerar essa busca pelo conhecimento, pelo domínio e pela necessidade de evoluir junto com as demais gerações. A intimidade com os recursos eletrônicos tornase o passaporte para modernidade, "obrigatório para os novos formatos de cidades e modelos de vida que estão sendo instaurados" (Côrte e Couto, 1999, p. 10-11).

Conforme Jones \& Bayeen (1998) algumas investigações sobre a aprendizagem da informática baseiam-se na pesquisa da cognição durante o processo de envelhecimento. Esses estudos dão suporte ao planejamento do ensino e implementação de atividades de Introdução à Informática voltadas especificadamente para a terceira idade. Estabelecemse propostas de acordo com suas necessidades, num processo cognitivo que atenda ao seu ritmo, suas limitações e deficiências sensoriais.

\section{Atelier Digital: relato de experiência de atividades com Terceira Idade na Feevale}

O Programa Terceira Idade na Feevale iniciou suas atividades em abril de 1993, a partir da proposta de palestras sobre temáticas diversificadas. Com o passar do tempo, percebeu-se a necessidade de oferecer outras atividades que envolvessem aspectos físicos, educacionais e culturais para essa população. Assim, a partir de 1995 iniciaram atividades de hidroginástica, alongamento, coral e teatro. Foi a partir de 1997, que a terceira idade contou com cursos de informática básica. Essa proposta inicial foi evoluindo para a construção de ações em conjunto com os idosos e seus interesses. No segundo semestre de 2006 iniciou-se a proposta do Atelier Digital. Atualmente são 
atendidos 20 alunos, dos quais $90 \%$ são do sexo feminino, $72 \%$ são casados, $35 \%$ são aposentados e $30 \%$ do lar, com uma faixa etária que varia de 46 a 78 anos, estando sua maioria na faixa entre 60 a 70 anos. Os participantes apresentam um nível econômico e cultural bastante variado.

O Atelier Digital faz parte dos projetos de extensão continuada do Centro Universitário Feevale. Estes estão baseados nas necessidades prementes e propostas oriundas da própria clientela que, analisadas junto a profissionais da área requerida e que atuam na Instituição, são encaminhadas para aprovação final pela mesma. O presente relato teve, portanto, como público alvo a turma de Terceira Idade que freqüenta atualmente as atividades do "Atelier Digital". Promove a inclusão digital a partir do atendimento individual das demandas de desenvolvimento e apropriação.

Os encontros iniciaram com a explicação da proposta do Atelier Digital, do atendimento individualizado sem perder o foco que a turma terá atividades socializadoras e que a construção do conhecimento muitas vezes ocorrerá por meio de interações, buscando a construção colaborativa e coletiva no uso das técnicas informatizadas e dos recursos computacionais, pois se acredita que é na construção que ocorrem as apropriações dos conhecimentos e habilidades buscadas pelos idosos ao participar do programa.

A seguir foi realizado um trabalho com um questionário, cujo objetivo foi identificar inicialmente as expectativas, habilidades e conhecimentos, bem como as necessidades e buscas individuais.

O resultado deste questionário nos revelou que doze dos participantes não tinham conhecimento sobre o uso do computador, cinco relataram ter um conhecimento básico, dois já haviam freqüentado um semestre de aulas para terceira Idade na Feevale e um participante já havia realizado dois semestres, ou módulo como era denominada a sistemática anterior, que considerava o formato de aula de informática como forma de incluir e levar à aprendizagem. Constata-se com isto que a turma é heterogênea e diversificada em todas as variáveis que se pretende atender.

No tocante às expectativas com o Atelier digital, em conseqüência da maioria não ter conhecimento da tecnologia, o "aprender tudo" foi à resposta em maior número obtida, seguida por uso da máquina Digital (funcionamento e programa para trabalhar as fotos), Internet, baixar músicas, segurança Antivírus, instalação de programas, MSN, Orkut, jogos, Excel, PowerPoint, vídeos, criar páginas e nomenclatura e uso das teclas.

A busca pelo conhecimento os faz sentirem-se incluídos tanto no convívio com a família quanto com a sociedade. Sentem que ainda tem capacidade de aprender e interagir de forma dinâmica com o computador. Os que ainda estão no mercado de trabalho procuram a informática pela capacitação e eficiência em sua vida profissional. Entre os que relataram que gostariam de aprender a usar a máquina fotográfica digital e como poderiam baixar e fazer modificações nestas fotos, manifestaram o desejo de enviar fotos para os filhos que "estão longe". Demonstraram também interesse em baixar músicas. O item segurança (antivírus) também não foi esquecido por eles, como forma de se protegerem de ameaças digitais. Programas de conversação foram sugeridos em virtude da comunicação a distância com filhos, netos e amigos.

Partindo destes resultados começou-se o planejamento das atividades. Foi elaborado um roteiro para as atividades. No início de cada atividade faz-se uma revisão, relembrar sobre os assuntos tratados no encontro anterior, pendências e dúvidas a serem esclarecidas. Partindo-se em seguida para uma atividade comum a todos e para o atendimento individualizado, encerrando-se com os acordos das atividades para o 
próximo encontro. É feito registro de todos os encontros, das atividades, pendências e dúvidas, assim como de todas as demandas. Estas atividades são ministradas por dois professores, no intuito de prestar um atendimento especializado, principalmente no tocante à individualidade.

A cada encontro são planejadas atividades que abrangem as diversas demandas, identificadas à medida que parte dos alunos apresentarem suas necessidades e desejos em relação àquilo que desejam conhecer e dominar com relação às tecnologias.

Durante os encontros são trabalhados também questões de postura e condicionamento físico, pois considerando o público da terceira idade é normal ocorrer situações que geram desconforto físico pelo uso do teclado e do mouse, inclusive pela forma como se posicionam frente ao computador. São trabalhadas técnicas de alongamento e relaxamento, numa parceria com o programa de Educação Física, que também atua com atividades específicas para o idoso.

Com relação aos encontros, no primeiro momento foi mostrado o procedimento de ligar e desligar o computador, pois para utilizar é necessário efetuar o "logon" (todos os computadores estão conectados em rede na Feevale), com usuário e senha específica para a turma. Essa ação de "logon" muitas vezes é diferente daquela que o usuário se defronta ao utilizar o computador na sua casa, tendo sido destacado e salientado as diversas formas possíveis que podem surgir considerando-se as diferentes versões do sistema operacional, no caso, o Windows.

$\mathrm{O}$ uso do mouse foi a primeira dificuldade a ser vencida, seguido do uso teclado e resolução da configuração de vídeo. Importante salientar que, por "default", não é permitido alterar configurações das máquinas, mas foi obtida autorização e a devida liberação para que o usuário possa adequar as interfaces visuais, tais como definição de tela, tamanho de fontes, de ícones, cores, etc., as suas necessidades e dificuldades.

No caso das interfaces, assim como as atividades de alongamento, foram consideradas as premissas de usabilidade e acessibilidade necessárias para dar ao idoso as condições para aproveitar melhor e da forma mais eficaz os recursos do computador, evitando-se dessa forma a desmotivação caso a busca pelo conhecimento transforme-se em frustração causadas pelas dificuldades de acesso e uso.

A partir da percepção de que o sujeito interage e faz parte de um meio social e que possui necessidades comuns do coletivo, são realizadas oficinas específicas, visando o desenvolvimento do grupo. A primeira oficina oferecida foi: "Usando mouse e teclado", onde foi dada ênfase em explicar as teclas e atalhos do teclado, utilizando-se softwares educacionais "freeware" para que pudessem treinar o uso dos mesmos. Uma aluna relata quase no final da oficina, "me concentrei tanto no software que estou usando o mouse já sem perceber (com segurança). Antes o dar dois cliques rápidos e o arrastar era tão difícil, como pode ter de repente ficado assim fácil?".

Também foi percebida uma ansiedade grande para o uso do e-mail, sendo que muitos não tinham endereço de e-mail, surgindo então a oportunidade de iniciar as ações de relações virtuais, conforme planejado, iniciando-se por esse recurso fácil e tapo abrangente atualmente que é o correio eletrônico. Para atender essa demanda uma segunda oficina foi oferecida, denominada de "Criando e gerenciando e-mail".

Lendo e analisando os primeiros e-mails recebidos pelos alunos percebe-se o empenho e a dedicação, demonstrando que a cada tarefa realizada torna-se uma grande vitória, pois mais do que aprender, usar adequadamente o computador e todas as técnicas e recursos 
possíveis significam um passo para tornarem-se agentes e autores de sua própria história, como foi possível perceber pelos relatos dos primeiros e-mails recebidos:

Rosângela, estou adorando as aulas de informática. Comecei não sabendo nada. Agora já consigo ligar o computador. Depois de cada aula, saio com novidades. Sintome gratificada com o aprendizado. Beijos Lílian”.

"Querida Rosangela obrigada pela tua atenção conosco. Você é uma pessoa muito especial,Deus te abençoe. Tchau Marilene.”.

"Oi Diana. Estou escrevendo a minha primeira mensagem. Estou enviando cópia para a Rosangela que é a orientadora do curso. Gente boa e dedicada. Um abraço Albery”.

"Oi, profe, como vai você? Estamos testando nossos conhecimentos. Que tal? (9) TCHAUUU, ABRAÇO, MARLISE”.

"QSP) Desejo um bom feriado para ti e tua família. Gostei muito da aula de hoje, pois apreendi bastante. 9 Áurea”.

Desde o início das atividades forma utilizados os termos da informática do cotidiano para quem convive com a realidade de computadores, redes, tecnologia e internet. Procurou-se dessa forma levar aos idosos as nomenclaturas e termos que passaram a fazer parte do linguajar de quem conhece e convive com a tecnologia.

Palavras e expressões como software, hardware, Word, peopleware, Windows, Linux, mouse, link, clicar, site, offline, online, navegar, MSN, modem, entre tantas outras, pareceram num primeiro momento difíceis e estranhas, mais parecendo, como comentado por um dos alunos "uma sopa de palavras ou uma aula de inglês".

Ao invés de traduzir ou explicar com outros termos correlacionados, procurou-se tornar esses termos parte do dia-a-dia durante os encontros, tendo sido trabalho também que cada aluno fizesse a própria busca pelo significado da palavra, criando-se um dicionário de termos onde todos os alunos foram os autores do conteúdo, conforme citado posteriormente nesse artigo nas considerações finais. Essa estratégia trouxe os resultados esperados, pois após alguns meses de encontros é natural ouvir conversas entre colegas sobre a forma como fez o download de um software a navegar por um site na internet.

A seguir estão relacionadas algumas atividades planejadas e já realizadas no Atelier Digital:

- Paint - Desenvolvendo arte, criando cenas, construindo um mundo mais colorido;

- Quem sou Eu? - atividade desenvolvida no editor de textos;

- Pastas e arquivos;

- Internet - Dicas de pesquisa na Internet;

- Internet - Como procurar e salvar figuras e textos;

- E-mail - gerenciando seu e-mail;

- Dicionário de termos da informática;

- Excel - Algumas atividades;

- Câmera Digital - uso e gerenciamento de fotos; 
- Uso de formulários interativos: site do Atelier Digital na WEB

Há cada novo encontro, novas dúvidas são trazidas, em função de um dos alunos ter feito alguma tentativa em realizar algo diferente no computador, seja em casa ou outro momento fora do Atelier Digital.

Essa busca pela descoberta demonstra o empenho em buscar a aprendizagem fora do espaço de sala de aula, com a autonomia e a crença de que é possível aprender e descobrir por conta, avançando quanto ao uso e domínio das tecnologias nas práticas do seu cotidiano.

\section{Trabalhos futuros}

Como trabalhos futuros junto ao público da terceira idade, serão utilizados os resultados do que se percebe a cada encontro com o intuito de colaborar na elaboração de material didático especializado para $\mathrm{o}$ idoso, atendendo às premissas de usabilidade $\mathrm{e}$ acessibilidade, no desenvolvimento de uma inclusão digital contextualizada e integrada ao cotidiano dos sujeitos.

Outra iniciativa é a criação de aplicativos, todos no formato de software educativo, específicos para atender às demandas e necessidades do idoso, utilizando-se ao máximo as técnicas de programação, lógica e adequação de interfaces, atendendo às particularidades dos sujeitos, ao mesmo tempo suas necessidades tanto cognitivas e sociais quanto suas dificuldades físicas.

Um espaço na WEB para o Atelier Digital já é uma realidade, em fase de organização final, já publicado e disponibilizado para os alunos atuarem como autor de seus próprios materiais, resultantes dos encontros e uso das aplicações, por enquanto textos do Word e desenhos do Paint. Com o uso de linguagem de scripts e banco de dados, foi possível criar um espaço de interesse comum, onde o idoso interage e constrói suas relações por meio de formulários e telas interativas, tornando possíveis ações socializadoras, integrando-se dessa forma à proposta do Atelier Digital.

Nesse espaço estão sendo programados e disponibilizados alguns recursos que permitem ao idoso participar de uma comunidade onde as relações sócio-afetivas são incentivadas como forma a permitir a cada sujeito sentir-se parte de um coletivo que aprende e interage de forma colaborativa. O dicionário de termos da turma é um exemplo desses recursos, bem como o cadastro de alunos, o mural de recados, entre outros.

\section{Considerações Finais}

Mais do que os resultados levantados junto às pesquisas, muitas vezes respondidas de forma aleatória, independente da questão em voga, o idoso busca seu espaço para ser agente da transformação. Oriundo de uma geração que sempre deteve o poder e a decisão final, mais destacado na região culturalmente alemã e italiana, como é o caso da comunidade da Feevale, essa geração passou a conviver com tecnologia e recursos onde sua experiência de vida, sua maturidade pelos anos de vivência já não fazem a diferença. Pelo contrário, o idoso é afastado de máquinas, da tecnologia, por motivos próprios de repúdio à inovação, ou pelo entendimento de que os idosos não possuem conhecimento, habilidade e os cuidados, para usar computadores e a tecnologia.

O que o idoso busca não é somente conhecer computadores e dominar sua lógica, mas apropriar-se, fazer parte, incluir-se como parte ativa e motivada em fazer acontecer na sociedade. "Esse público é tão exigente quanto a sociedade moderna lhe exige que seja um sujeito ativo, ou muitas vezes dentro de uma situação paradoxal, essa mesma 
sociedade vê o idoso como um sujeito experiente pelos processos e ações vivenciadas, mas carente de habilidades e conhecimentos inovadores. E dentro dessa realidade as Tecnologias, vistas como inovação e avanço na forma de fazer tornam-se recursos e técnicas procuradas e demandadas para proporcionarem a esses sujeitos, uma forma de se mostrarem necessários, úteis e atuantes" (Passerino; Pasqualotti, 2006).

Outro característica percebida é a grande dedicação na busca em dominarem a tecnologia, a cada atividade por eles vencida é uma vitória que comemoram como grande conquista no seu processo de desenvolvimento e aprimoramento.

\section{Referências Bibliográficas}

DIAS, Cláudia. Usabilidade na WEB. Criando portais acessíveis. Rio de Janeiro-RJ: Alta Books. 2003.

CÔRTE, Beltrina, COUTO, Edvaldo S. Colonização tecnológica do corpo/urbano: a remodelagem da vida. Revista Kairós - Gerontologia. / Núcleo de Estudo e Pesquisa do Envelhecimento. São Paulo: EDUC, Ano 2, nº 2, 9-26p. 1999.

FEEVALE. Programas de extensão para a $\mathbf{3}^{\mathbf{a}}$ idade. Disponível em http://www.feevale.br/internas/default.asp?intIdSecao=232\&intIdConteudo=1307. Acesso em 13 nov. 2006.

IBGE - Instituto Brasileiro de Geografia e Estatística. Disponível em: $<$ http://www.ibge.gov.br/>. Acesso em: 04 mai. 2006.

JONES B. D. \& BAYEEN U. J. Teaching older adults to use computers: Recommendations base don cognitive aging research. Educacional Gerontology, 24 (7): 675-689, oct-nov. 1998.

JORGE, Robson de Farias. Informática na $3^{\text {a }}$ idade. - Usando o computador Revista Rio Total - Feliz Idade (Revista Eletrônica), 2006. Disponível em: http://www.riototal.com.br/feliz-idade/. Acesso em: set. 2006.

KACHAR, Vitória. Terceira Idade Informática: aprender revelando potencialidades. São Paulo: Cortez, 2003.

NOVAES, Maria Helena. Psicologia da terceira idade: conquistas possíveis e rupturas necessárias. 2.ed., Paulo Frontin-Rio de Janeiro: NAU, 1997.

PASSERINO, L. M.; PASQUALOTI, P. R. A Inclusão Digital como Prática Social: uma visão sócio-histórica da apropriação tecnológica em idosos. In: Portella, M; Gaglietti, M.; Pasqualotti, A. Envelhecimento Humano: saberes e fazeres. Passo Fundo: UPF, 2006.

PRETTO, N. Uma escola sem/com futuro. Campinas-SP: Papirus, 1996.

SÁ, M. A. O idoso e o computador: condições facilitadoras e dificultadoras para o aprendizado. Dissertação de Mestrado em Educação: Psicologia da Educação, PUC/SP, 1999. 